NOOMI: THE FULL EXPERIENCE OF STARTING AN ONLINE STORE

By

Nadia Rassoul

Honours Bachelor of Commerce (Management), York University, June 2017

a MRP
presented to Ryerson University

in partial fulfillment of the

requirements for the degree of

Master of Digital Media

in the program of

Digital Media

Toronto, Ontario, Canada, 2018

(C) Nadia Rassoul, 2018 


\section{AUTHOR'S DECLARATION FOR ELECTRONIC SUBMISSION OF A MRP}

I hereby declare that I am the sole author of this MRP. This is a true copy of the MRP, including any required final revisions.

I authorize Ryerson University to lend this MRP to other institutions or individuals for the purpose of scholarly research.

I further authorize Ryerson University to reproduce this MRP by photocopying or by other means, in total or in part, at the request of other institutions or individuals for the purpose of scholarly research.

I understand that my MRP may be made electronically available to the public 


\title{
Abstract \\ NOOMI: THE FULL EXPERIENCE OF STARTING AN ONLINE STORE
}

\author{
Nadia Rassoul \\ Master of Digital Media \\ Digital Media \\ Ryerson University, 2018
}

Whoever said 'creating a startup is easy' clearly wasn't thinking straight. The term 'startup' in itself explains that you're starting something new. You - as the owner of your business are responsible for every move and every decision. The preliminary stages are the most crucial for startups and therefore, a marketing plan and use of storytelling must be compelling for customers and investors. The purpose of this project is to share my experiences throughout the process, providing an overview of my marketing strategy and discussing how I overcame the challenges I faced. I will also be touching on the "why" factor. Why did I decide ecommerce was the path I wanted to embark on? Additionally, I'll share how the MDM program influenced my decisions, the importance of social media for my business, and my future plans. 


\section{Acknowledgments}

Acknowledgements I have been fortunate to receive the support of many remarkable people throughout my master's studies. To my supervisor, Ahmed Sagarwala: You were one of the first people I shared my idea with and supported me throughout. Your guidance, unwavering support, and insight made what seemed a dream at the time, into a tangible reality. To my professors during the first semester, Richard Lachman, Sean Wise, and Alya Naumova: I entered this program with a dream I wanted to pursue and you were all the ones who made me believe in myself and that everything is possible and achievable. To my professors during second semester, Gregory Levey and Wojtek Kawczynski : You were there from the start. You taught me so much and opened my mind to new possibilities. To the MDM 5.0 cohort: You inspired me to reach my goal. I learned so much and my motivation grew from each and every one of you. I am glad we got to share this enriching journey together. To my classmates, Nada, Marta, Ingrid and Ali: Each of you have helped me in different ways and I will always be grateful for that. To my support system, Osaid and Lyan: You two were there from the start and supported me throughout. Your ongoing encouragement and motivation kept me going and I wouldn't have imagined going through all this without you two. Finally, I would like to acknowledge with gratitude, the love and support of my family - my parents, Nagham and Ali; my sister, Noor: You have always cheered me on and believed in me. Words cannot express how grateful I am to have you all by my side. 


\section{Table of Contents}

Author's Declaration $\quad$ ii

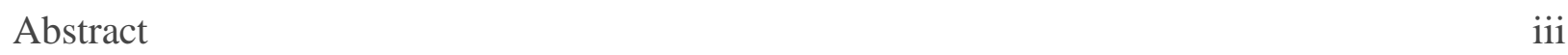

Acknowledgments

Table of Contents $\quad$ V

$\begin{array}{ll}\text { Introduction } & 1\end{array}$

How Noomi Began 1

$\begin{array}{ll}\text { Learning from Data } & 2\end{array}$

Solo Show $\quad 4$

Marketing Plan for Noomi $\quad 5$

$\begin{array}{ll}\text { Challenges } & 15\end{array}$

$\begin{array}{ll}\text { The Importance of Digital Media } & 18\end{array}$

What the Future Holds for Noomi $\quad 19$

$\begin{array}{lr}\text { Conclusion: What I Learned } & 20\end{array}$

$\begin{array}{ll}\text { References } & 21\end{array}$ 


\section{Introduction: What is Noomi}

Noomi is a lifestyle brand that showcases the beauty and heritage of Middle Eastern culture. Noomi products are carefully created to capture the culture's unique qualities while spreading an overarching empowering message. The majority of Noomi products are tailored to enhance independence and patriotism while representing the diverse and dazzling culture of the Middle East. The brand welcomes people of all races, sexes, ages and nationalities. Empowering each other, standing together, and maintaining peace and love are all characteristics of the Noomi brand.

\section{How Noomi Began}

Growing up, I moved to so many countries from Iraq to Canada to England to Jordan and then back to Canada. Throughout it all, I was constantly surrounded by Middle Eastern people. The culture captivated me and was part of my everyday life. Year by year, I was fascinated by the culture even more. However, the only time I got to represent the culture is by wearing traditional Middle Eastern clothing back home or wearing it in cultural events when I'm in England or Canada. Shortly after, I came to the realization that I wanted to develop a hybrid of modern clothing with a Middle Eastern spin on it.

My passion has always been meshing Business and Social Media Management. Since Toronto's startup community was growing immensely, I knew it was a perfect place to start my venture. When I moved to Canada to pursue post-secondary education, I took advantage of my business degree and found ways to combine it with my passion for social media. During my undergraduate degree, I joined a Middle Eastern organization. I met so many amazing people and 
I learned more and more about the Middle East, which only increased my yearn to do something in the upcoming future. It was then, during my undergrad where I had the idea to create a Middle Eastern fashion apparel company, but at the time, I was discouraged. I didn't have the resources or experience to jump into something so grand, especially considering the risk factor on creating a startup. As Forbes magazine stated, “Nine out of ten startups will fail.” (Patel, 2015) I wanted to find the best time to pursue the idea and be that $1 / 10$ that actually succeeds.

That is where my Masters and my MDM instructors and peers come into play. After taking Entrepreneurship and Startup courses, attending various conferences, and spending hours with my peers, I learned so much and my motivation grew and that's when I realized that I wanted to pursue my dream now. I spent months talking to graphic designers, suppliers, different companies, and attended various fashion and digital conferences. I explored several vendors to source the best quality at an affordable price for customers to wear. I spent a great deal of time planning marketing strategies for Noomi.

\section{Learning from Data}

The 25th of March, 2018 marks the official launch of Noomi. The product line included 5 sweaters, 5 shirts, 7 beanies, and 3 pins.
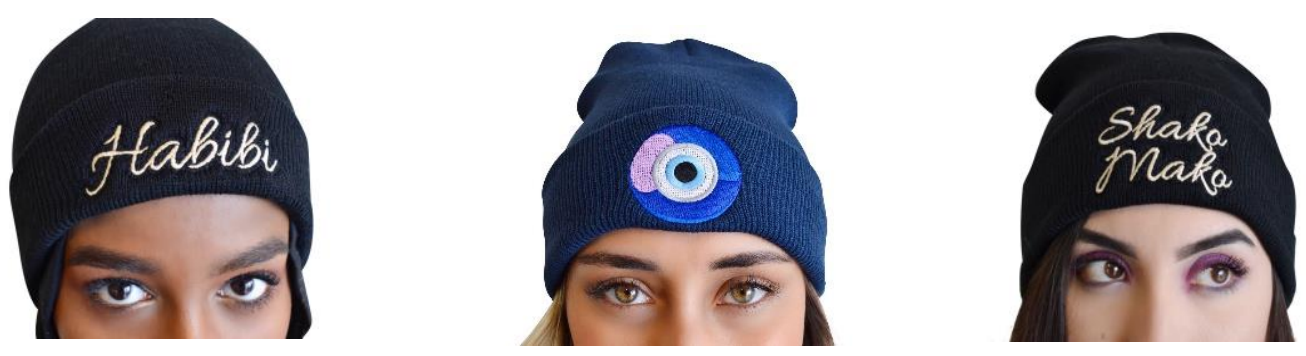

Photos taken by Nadia Rassoul 

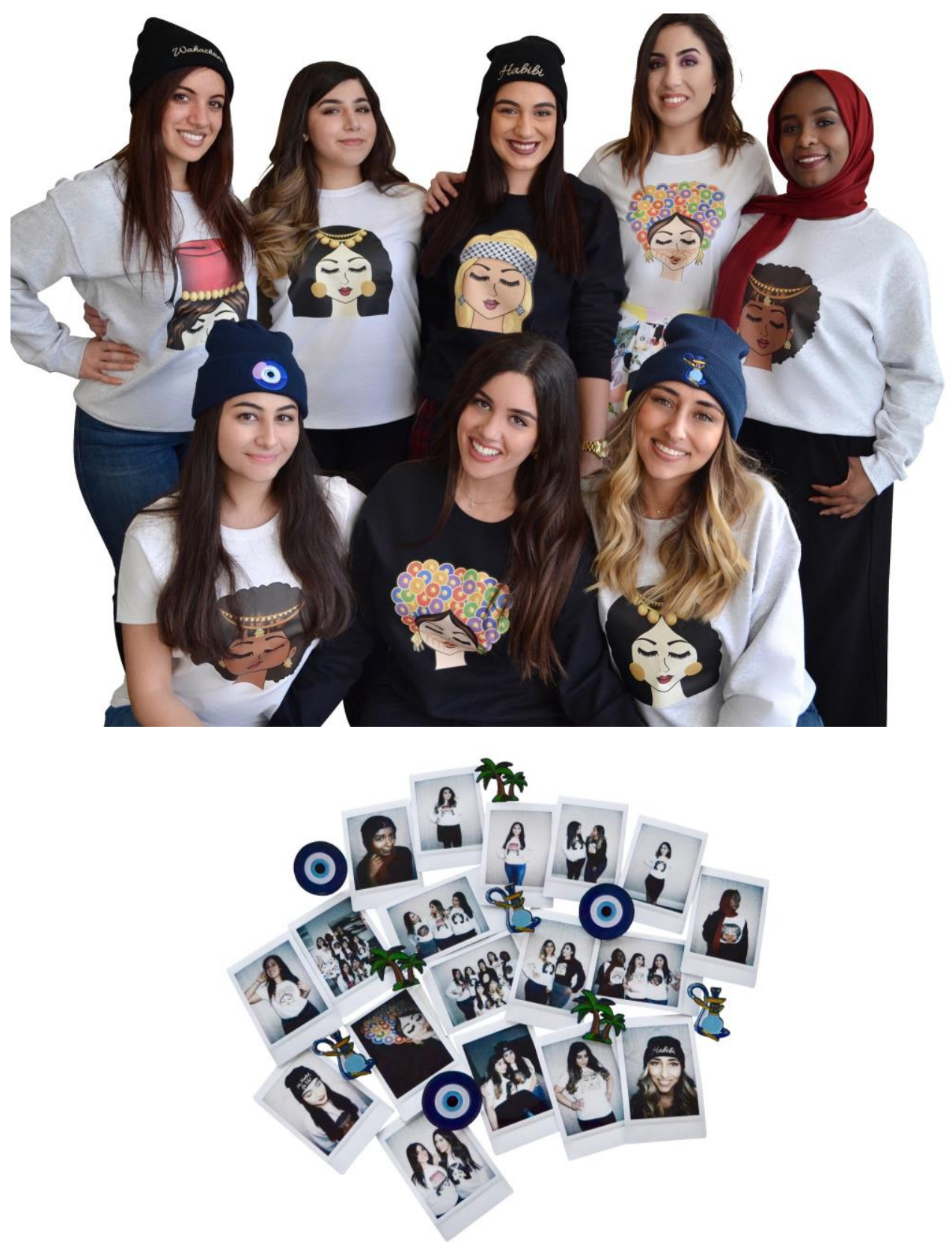

Pictures taken of the products during Noomi's photoshoot

There are countless designs I would have liked to launch for my brand, but I wanted to take the smart and safe route. I launched products in limited quantities to gain exposure first. I also wanted to gauge customer demand and determine what piques their interest based on the feedback. I was exposed to the importance of this factor and how companies should have a minimum viable product (MVP), as I learned in the program 100 Steps 2 Startup with Professor 
Sean Wise. "Getting to market with an MVP helps founders learn as quickly as possible. By definition, an MVP is the least sophisticated version of your solution that can be used for learning. The beginning is where most of the learning process is." (Wise, 2018). The immediate feedback post-launch was incredible! Initially, when creating Noomi, my target audience was females. Although my brand welcomes all races, sexes, ages and nationalities — women were my main target. I was pleasantly surprised to see how many men that supported and bought my products. I received a large number of emails requesting I launch unisex products. I also received requests to participate in Noomi's Brand Ambassador program, which will be mentioned in detail in the Marketing Plan section of this paper. The positive outcome motivated me to listen to my customers and strategize how I can achieve these goals. Listening to customers and using data through the analytics page on Noomi's Shopify account and through all the engagements on Instagram are crucial for the future of the company. That is why I am planning to launch unisex products for my next collection.

\section{Solo Show}

Starting a new business on my own isn't the easiest thing. I have to manage all aspects; the marketing, finances, content, designs, and customer service. There are certain roles I excel in due to my past experience, but there are other roles where I lack experience and need to use trial and error to learn from. Juggling all these roles as well as balancing my Masters can be a bit struggling at times but the way to solve it is all through time management. I believe time management is about making the most of your time. The more you value it, the better you'll manage it. Regardless of how stressful business management can be, I believe that having one person run the business is optimal at Noomi's early stages. In the future, when Noomi becomes 
bigger and more successful, recruiting more people would be required. However, as of now, the advantages of being a solopreneur outweighs the disadvantages. Although managing an entire business by myself is time-consuming and requires extensive amounts of effort, my diligence and drive to succeed leads me to persevere.

\section{Marketing Plan for Noomi}

Instilling a strong marketing plan is a crucial step for an ecommerce business. Noomi's target audience primarily targets the Generation Y audience. It's heavy usage of Instagram makes it an ideal focus as my primary medium for promotion.

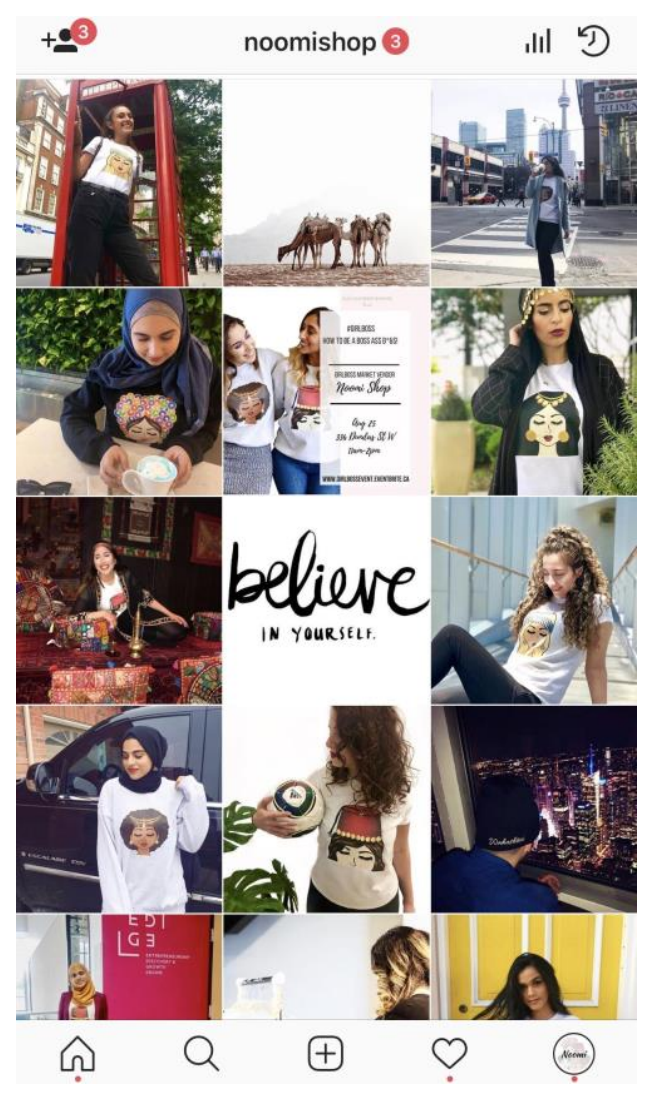

Noomi's Instagram page @noomishop

My first step was to create a countdown and create some anticipation for the product reveals as well as to gain followers for the account. 


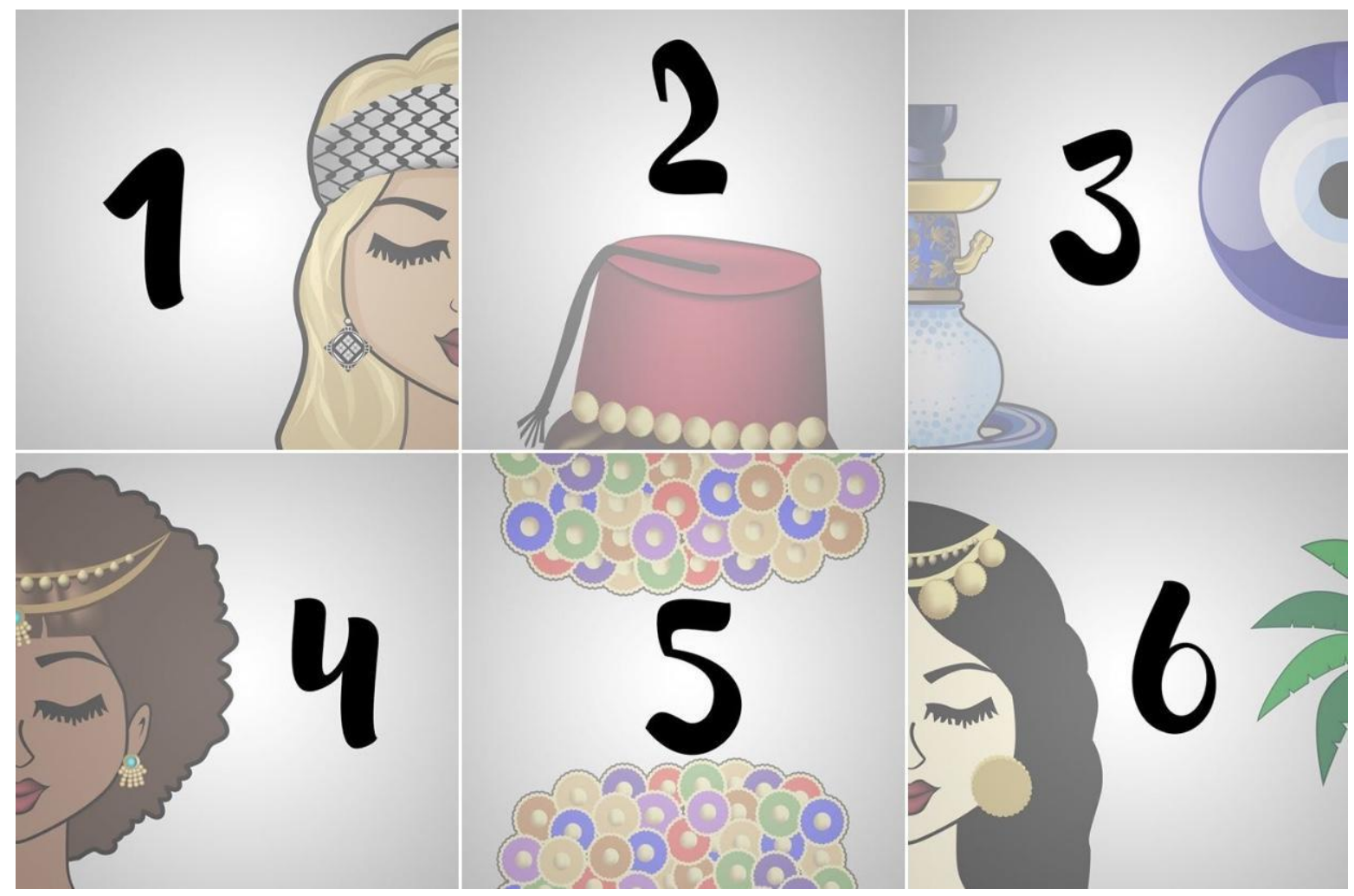

Countdown on Noomi's Instagram page

A major Middle Eastern event The 7th Annual Middle Eastern Gala took place one week prior to the launch of Noomi. This event is well known across the GTA and even the entire province of Ontario. The 1,000+ attendees at this event were all part of my brands' target audience. Noomi headlined as a sponsor at the event, which was a great marketing tactic as it was pre-launch. The logo was on all screens at the venue and all Noomi's flyers were places on the tables. Included in the sponsorship package were Facebook mentions of the brand. 

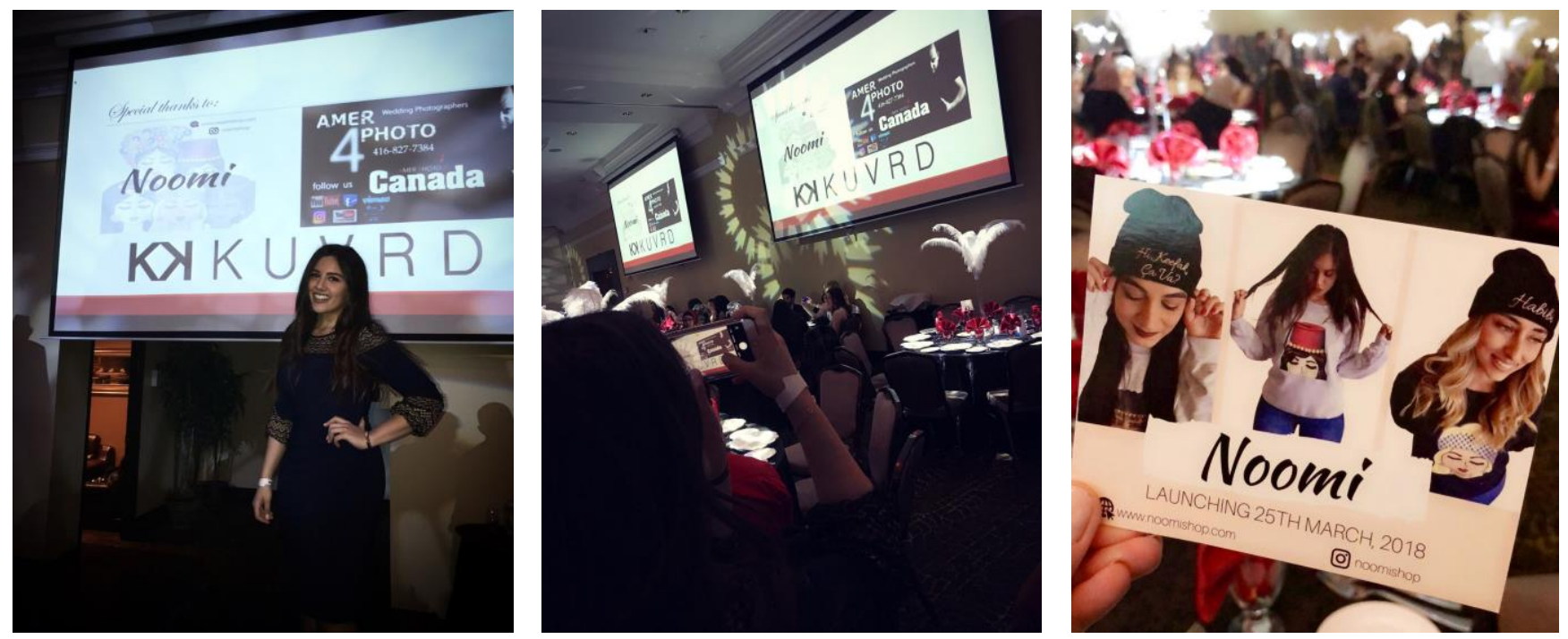

Noomi sponsoring at the 7th Annual Middle Eastern Gala

After the Gala ended, I faced a slight mishap with the organizers of the event; an agreed upon Facebook ad wasn't run. Other sponsors each received a detailed post with visuals, however Noomi's post was bare-bones. With every single other sponsor having an intriguing and professional post while Noomi didn't, I needed to act fast as it didn't look good for the brand nor does it make the company look legitimate. Therefore, I contacted the organizers immediately, providing them a photo of the company and a brief description I told them if it's not changed, I would rather have the whole post removed since I believe having an inadequate brand image is worse than having no mention at all. Thankfully, once I contacted them and relayed my concerns, they changed it right away.

Timeline of the Marketing Strategy prior to the launch date

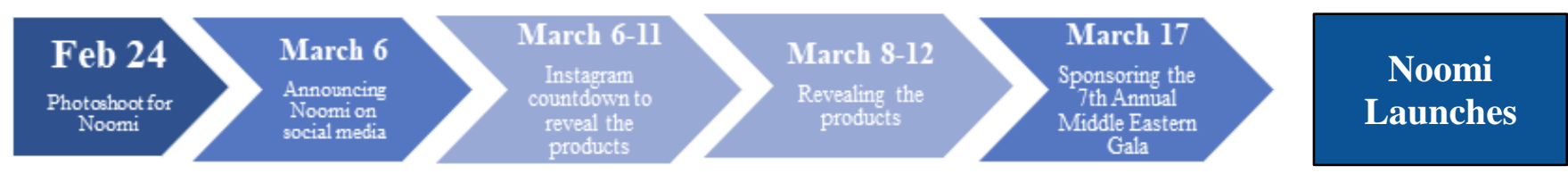


March 25, 2018 marked the official launch. The Noomi website was live and the launch party was taking place that afternoon. As part of my marketing plan, I had setup an Instagram countdown. People were buzzing with excitement not just online, but via word-of-mouth as well. I wanted to give everyone 'first access' to purchasing my products, which is one of the main reasons I decided to host the launch party. As part of the launch party game plan, I created a Snapchat filter as well as customized decor and photobooth props to solidify the brand's theme. I had signs across the room with the hashtag \#NoomiShop. I also provided guests with a 25 percent discount voucher card that they could use on the website, as well as share with friends. A photographer and videographer were hired to shoot future promotional material for Noomi.

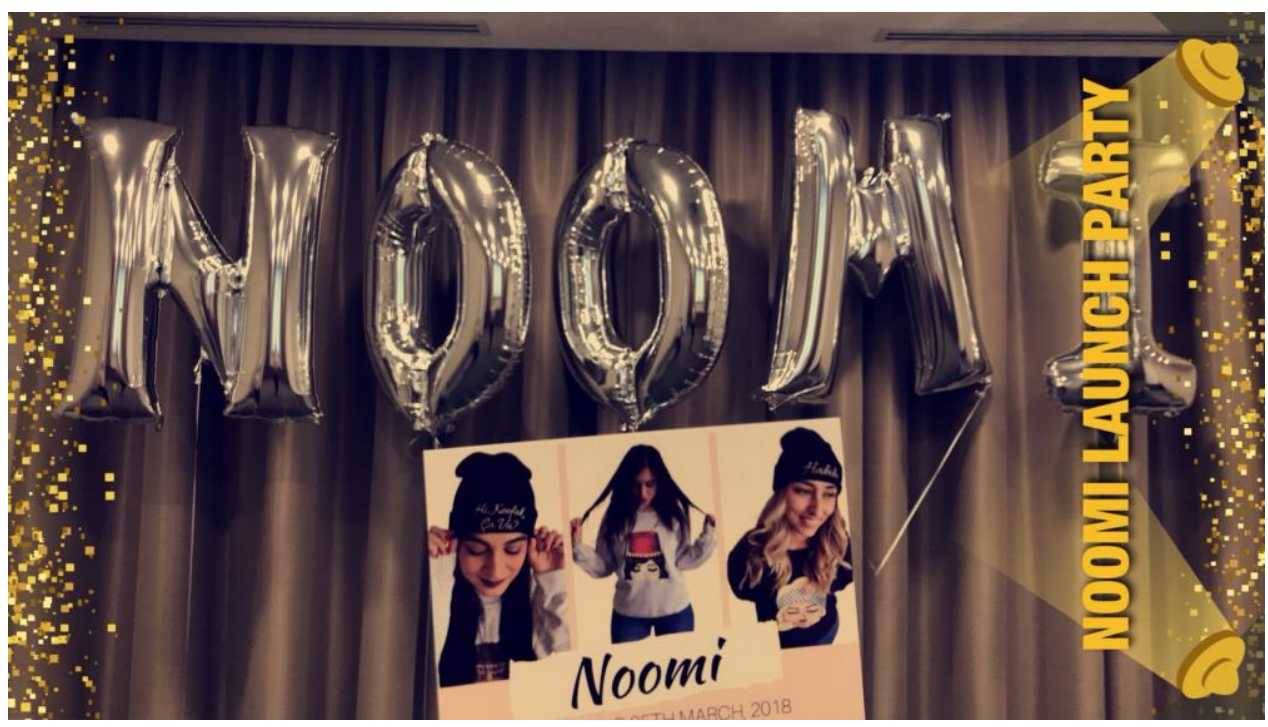



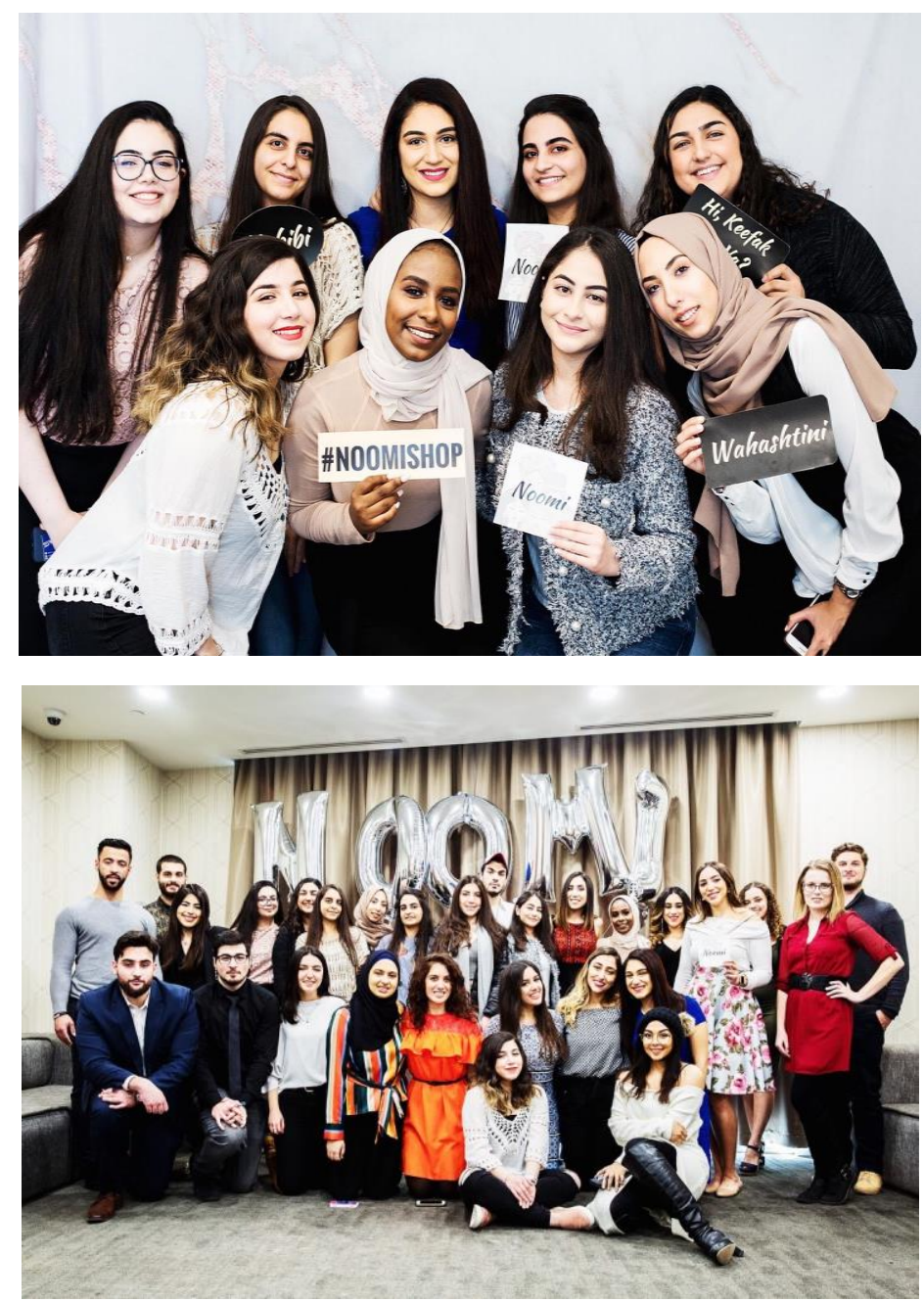

Pictures taken at Noomi's Launch Party

I really wanted to take advantage of the power that comes along with storytelling. I decided to share a short synopsis and history of the brand, the idea behind it, and the inspiration that came along with it (Fryer, 2003). As The First Round Review article, The Three Frameworks You Need to Kick-start Sales stated, "narrative is too often forgotten and it's a key to connecting with a customer." Thus, I wanted to share Noomi's story right from the beginning. 
The day after the launch party, Noomi had its first blog post where an attendee, Lyan Khazanchi wrote about the launch party. It described the storytelling approach to users and customers that were not in attendance, so they could see the importance of the company and how it came to be. The strategy allowed customers to become involved in the creation of the brand while marketing the brand to their friends. Through the use of hashtags and posts regarding the launch party on social media, Noomi became recognized by organizations and magazines. For example, the Mesopotamia Group, which has over 86,000 likes on Facebook, posted about Noomi's launch party. The same organization later featured Noomi in the May issue of their magazine. Influence magazine also featured Noomi on their very first issue in June.

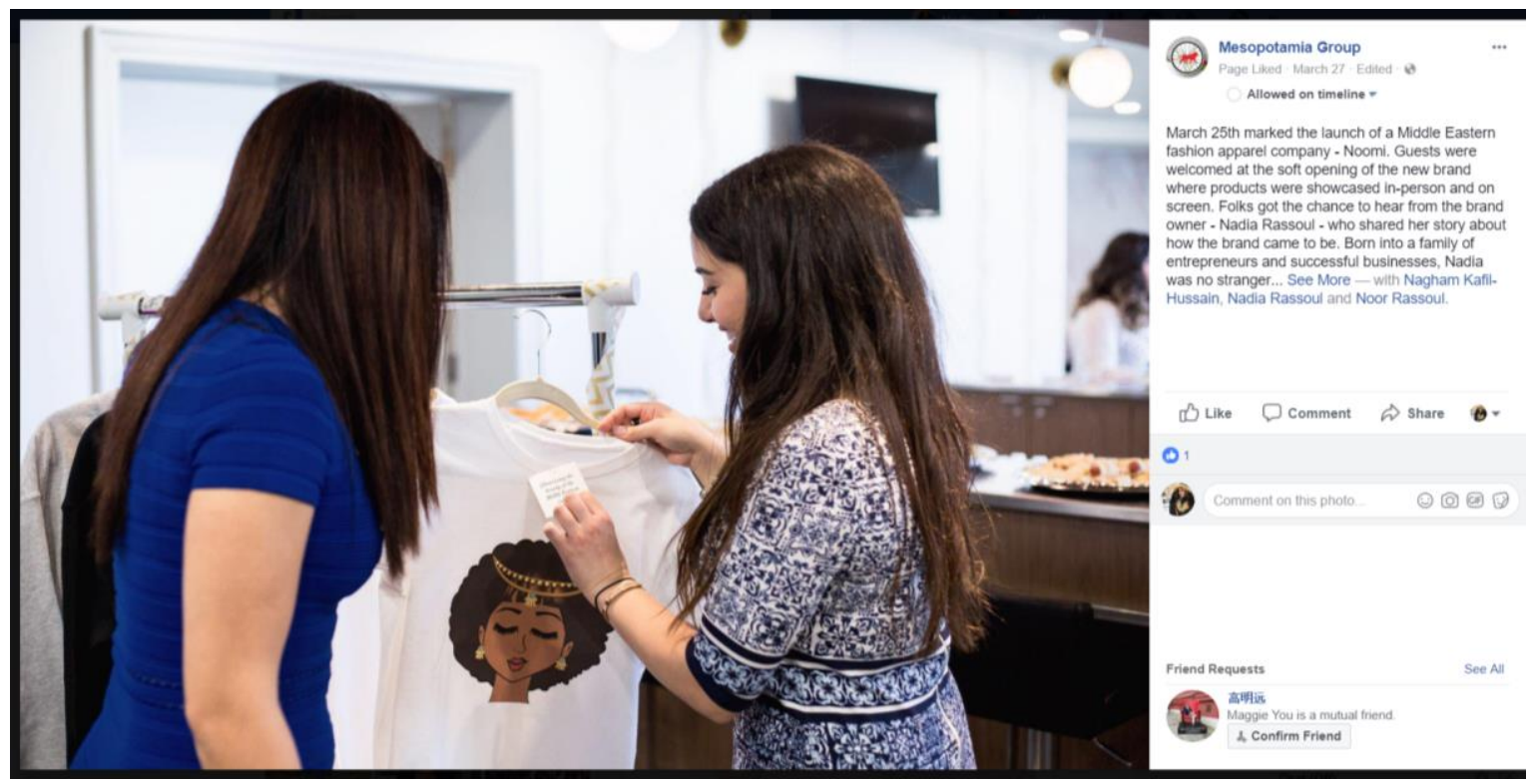

Mesopotamia Group's Facebook page 


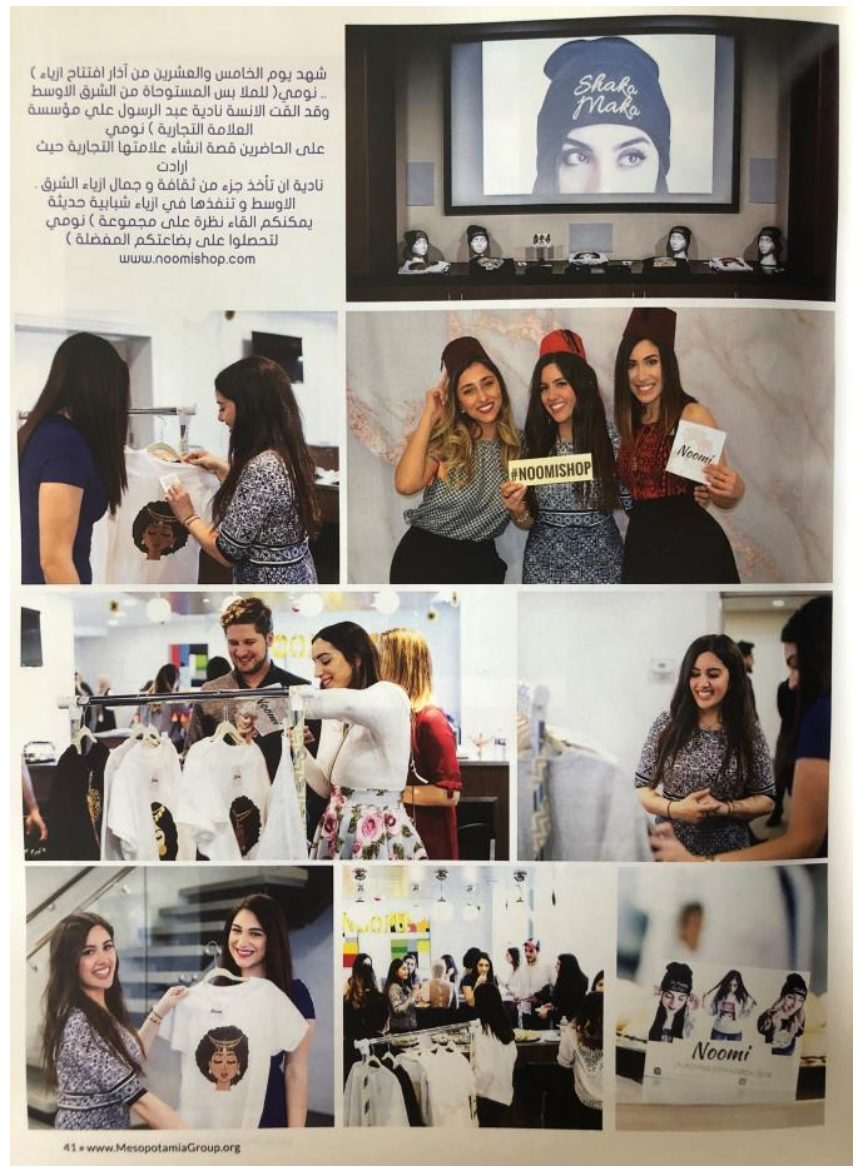

Mesopotamia Group magazine (May issue)

\section{Noomi Shop}

shot + written byemi zibaei
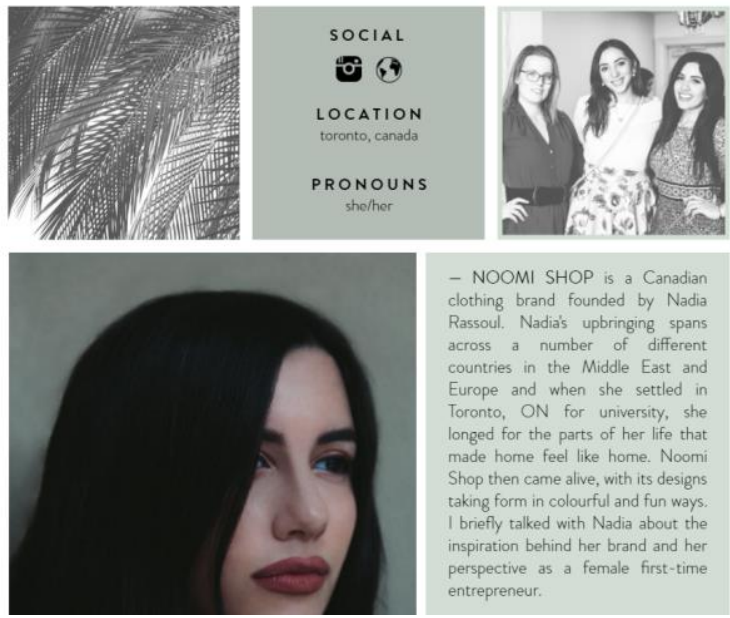

- NOOMI SHOP is a Canadian clothing brand founded by Nadia Rassoul. Nadia's upbringing spans across a number of different countries in the Middle East and Europe and when she settled in Toronto, ON for university, she longed for the parts of her life that me hor the parts of her life that Shop then came atve, with its designs Shop then came alive, with ins designs thriefly I brieny taked with Nadia about the inspiration behind her brand and her perspective
entrepreneur.

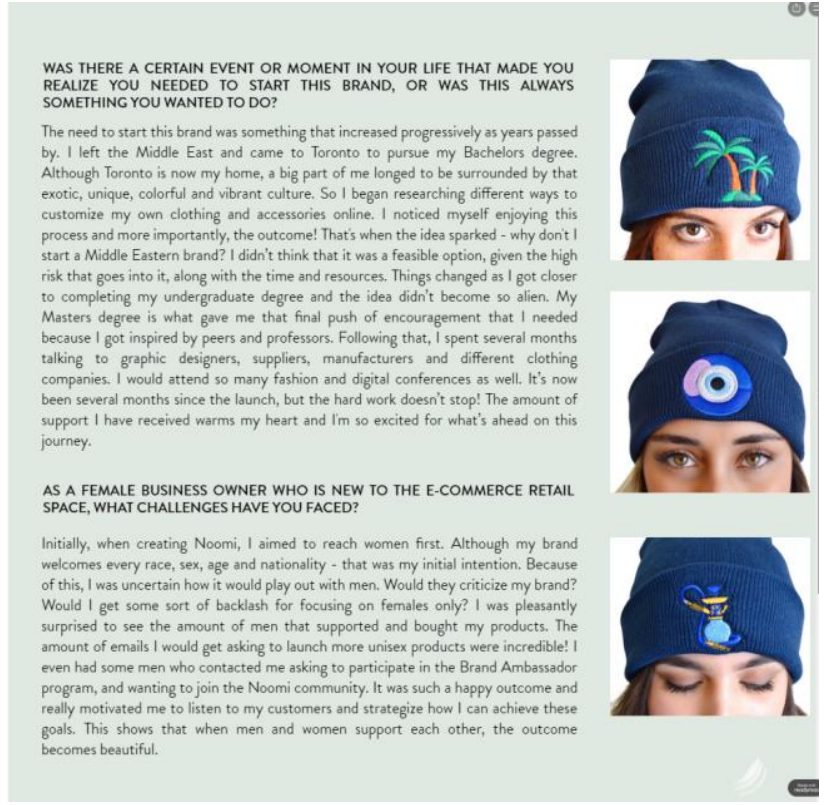

Influence magazine (June issue) 
Even though the first blog post received a high level of engagement and press, I didn't want to stop there, so I already started planning the next three upcoming blog posts, as Conrad Egusa stated "The work of building media coverage is never over." (Egusa, 2016).

Noomi sells its products online and that is how I identify it, as an ecommerce company. However, in the early stages, I want it to be recognized as much as possible, so I planned to attend various Middle Eastern events to increase exposure. Therefore, the week after Noomi launched, I went to Hamilton for the Arabian Nights event that McMaster University was hosting.

Even though I wanted to sell, my main goal was to increase exposure and have people learn about Noomi. Throughout the event, people approached me and stated, "You guys are from Instagram!" or "Your flyer was at the Middle Eastern Gala, right?" and "My friend went to the launch party!" Hearing these comments put me at ease that the results for the marketing plans I had for Noomi were successful so far.
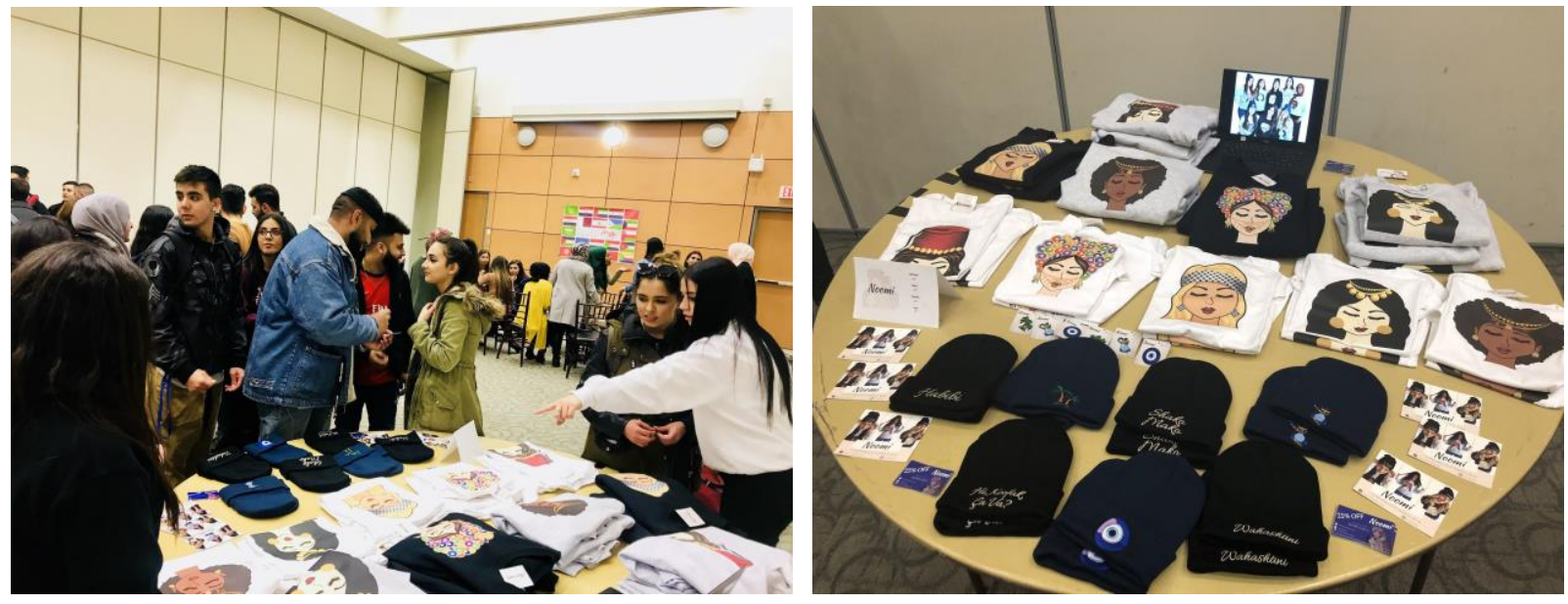

Noomi at Arabian Nights in McMaster University 
Furthermore, there are two types of marketing, traditional and digital. I wanted to try both different types to see which one would benefit Noomi most. I applied traditional marketing by placing flyers of Noomi downtown.

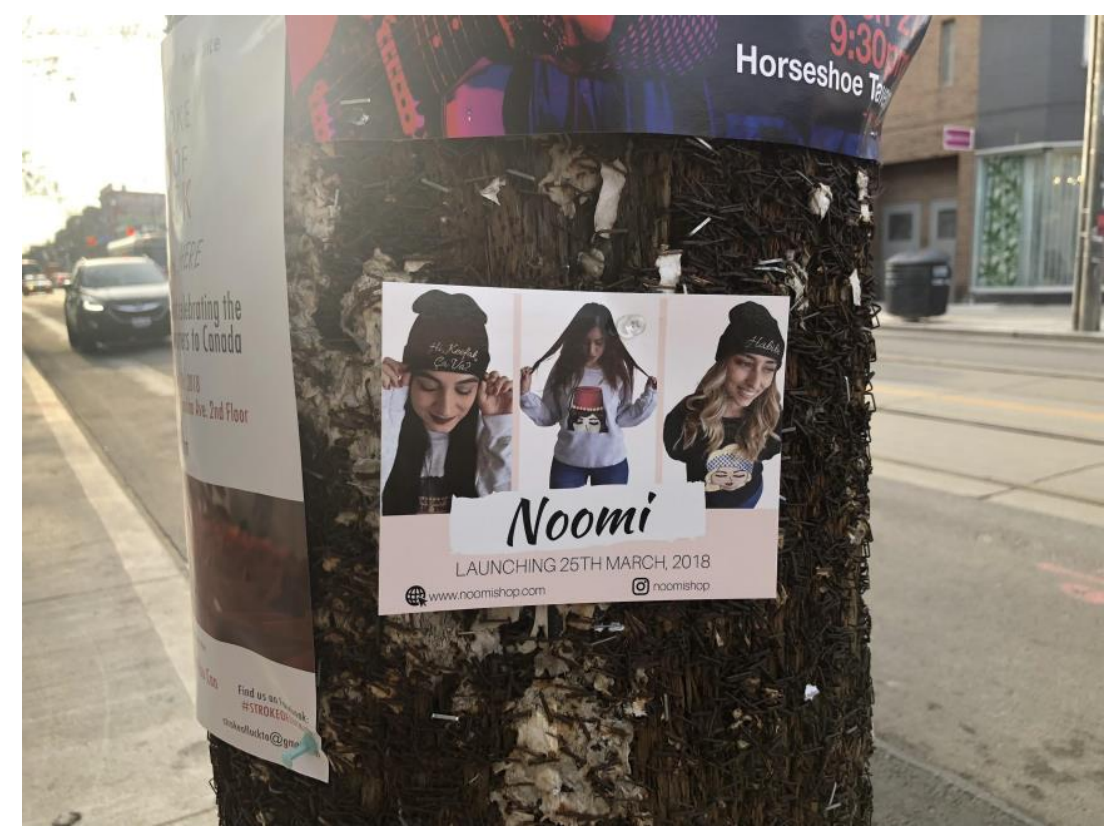

Noomi's flyer in Queen Street West, Toronto

Noomi was also featured in two magazines as previously mentioned. However, it was hard to track data with this type of marketing to know who accessed the website or Noomi's Instagram page or actually placed an order after seeing the ad. This was a problem because gathering data is crucial for Noomi. Finding out what customers are saying about the brand, which product they like the most, or which post gets the most engagement are all essential. It determines what I should focus on for the future for Noomi's designs. Also, traditional marketing focused on a local target audience, but I want Noomi to be known worldwide, especially since it's an ecommerce company and can take advantage of worldwide shipping. 
Social media has revolutionized the marketing landscape. It is one of the primary reasons why Noomi is doing so well. Social media allows Noomi to receive worldwide exposure and allows Noomi to build its very own community. Before the website's launch, Noomi's Instagram page received over 700 followers in less than one week. People were frequently reacting to posts or emailing with inquiries to purchase products. Once the products were launched, half were sold out in less than 2 weeks. Furthermore, not only do I want to interact with the customers as much as possible to provide great customer service, but creating a Brand Ambassador program is something I believe Noomi will benefit from. Noomi offers special perks to Brand Ambassadors such as personalized referral codes and profile features on the social media pages. Ambassadors will also get the chance to be a face of the brand and participate in photo shoots. Using Brand Ambassadors to build a community for Noomi is an effective marketing strategy.

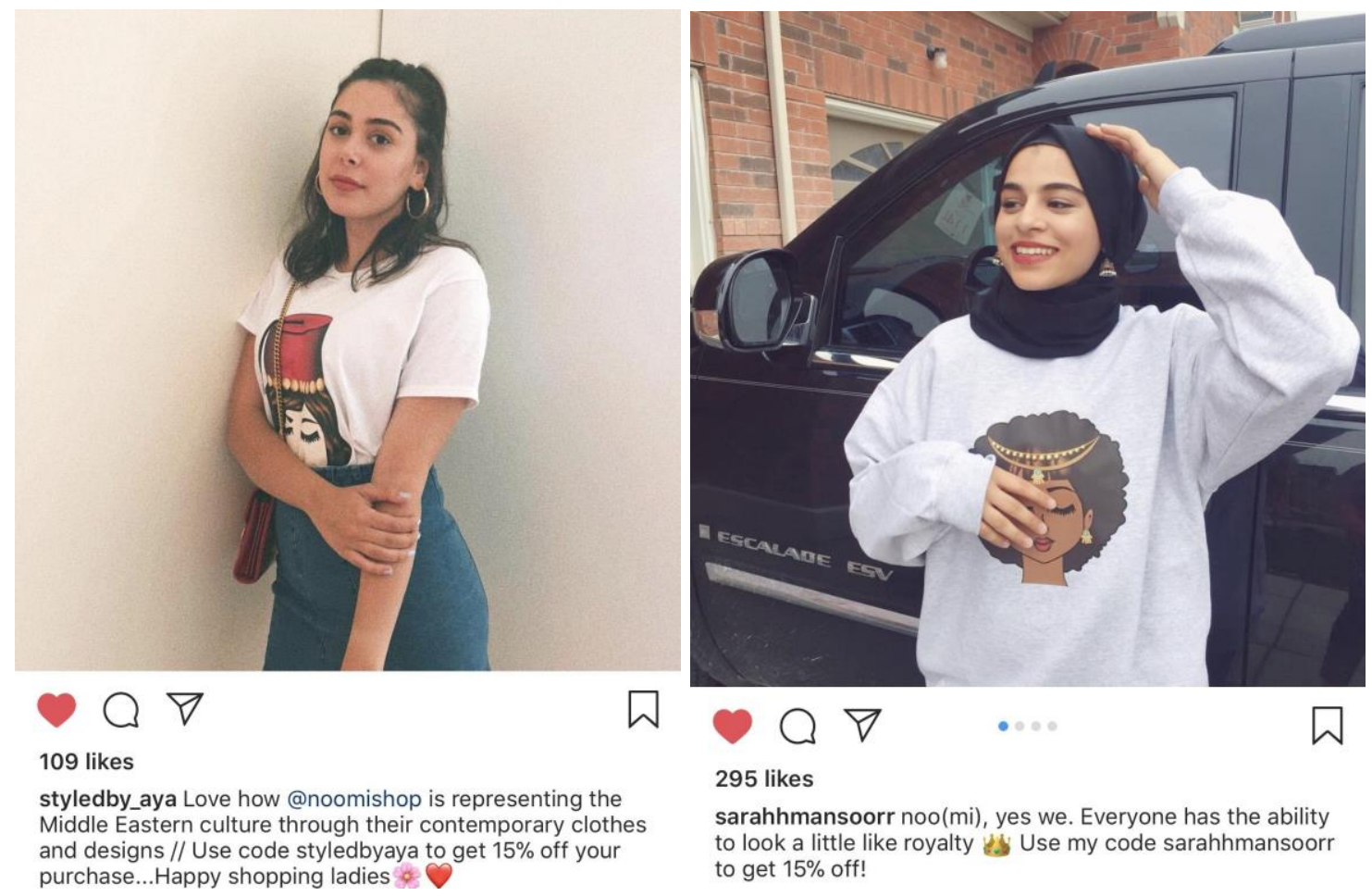

Brand Ambassadors posting on Instagram about Noomi 
The way it works is that each Brand Ambassador receives $25 \%$ off on all orders created, provided they send us back pictures to feature on our page. A $15 \%$ off referral code is provided to all contributors of featured photos. Therefore, sales are made through brand ambassadors and free user-generated photos of them wearing the products are used to promote the brand. A unique referral code is provided to ambassadors, that would make them want to post the pictures on their own account wearing the products and telling their followers to purchase Noomi as well. It's a win-win situation.

\section{Challenges}

Exciting as it is to create the startup I have always wanted to do, there were several stressful situations during the process. Doing something new for the first time is all about trial and error. Even though I studied Business Management, am completing a master's degree in Digital Media, and attending entrepreneurial and fashion related conferences and events, that doesn't mean mistakes won't occur nor would there be any challenges I would have to face. No matter how much knowledge and passion a person has, they will always learn something new through firsthand experiences. There are a few challenges I had to face while starting Noomi, one of which was dealing with a supplier. Noomi’s pins were supplied by an international company, while all other products were sourced from Canada. Dealing with the pin supplier was stressful. At first, they took over a month to ship the order, then they wrote an incorrect invoice that required me to pay five hundred dollars to customs, which took weeks to dispute it at the border. However, it wasn't only their slow service nor their mistakes that caused the problem. The issue grew bigger when the suppliers handled the situation unprofessionally by not admitting their mistakes. I 
finally received the pins after two months of ordering them. However, some of the pins were incorrectly produced.
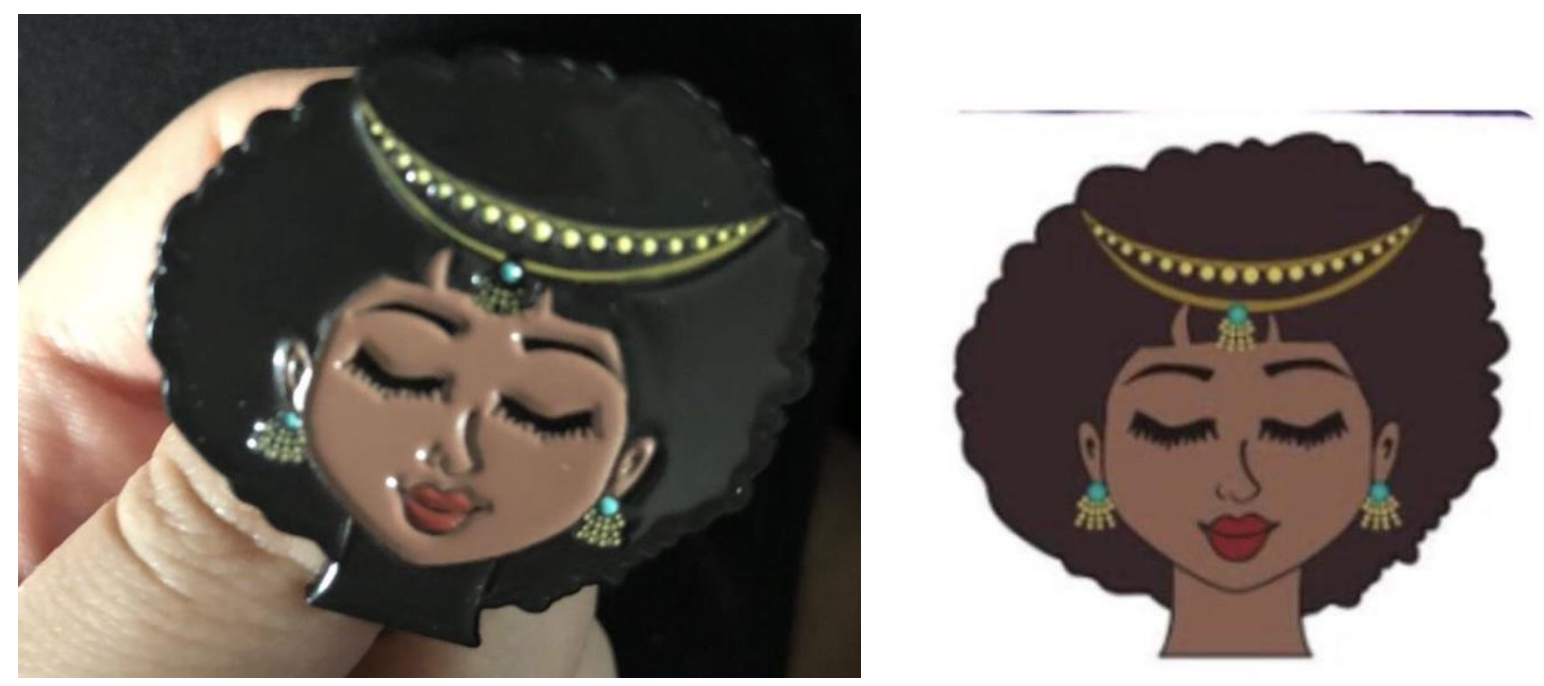

Noomi pin that was incorrectly done (colour of the neck)

How the pin was suppose to look like

Noomi's launch party was one week away, so when I finally received the pins that turned out to be faulty products, it made of a stressful situation. I had to pivot and change my plans and launch 3 pins instead of the 8 I was hoping to do. This experience taught me that certain things don't always go to plan and it's the way you handle the situation that will determine a positive or negative outcome.

Another challenge I faced related to managing inventory. Once Noomi was launched, there were a lot of sales and six items were completely sold out. I contacted my suppliers and reordered all my products in higher quantities. My mistake was that I ordered the same number of shirts, sweaters, and beanies, but since it was the spring season, more shirts were getting sold than the sweaters and beanies. I should have used the sales data to determine exact quantities. Sales for 
upcoming months must to be associated to the correct season and unused inventory will take up storage space.

I still want to attend events and sell in person just to increase exposure as much as possible during the early stages. Because Noomi did so well when tabling during the Arabian Night at McMaster University, I began to search for other events I can go to. Toronto Designers Market in downtown Toronto offers a place to do a popup so I thought that would be great to try.

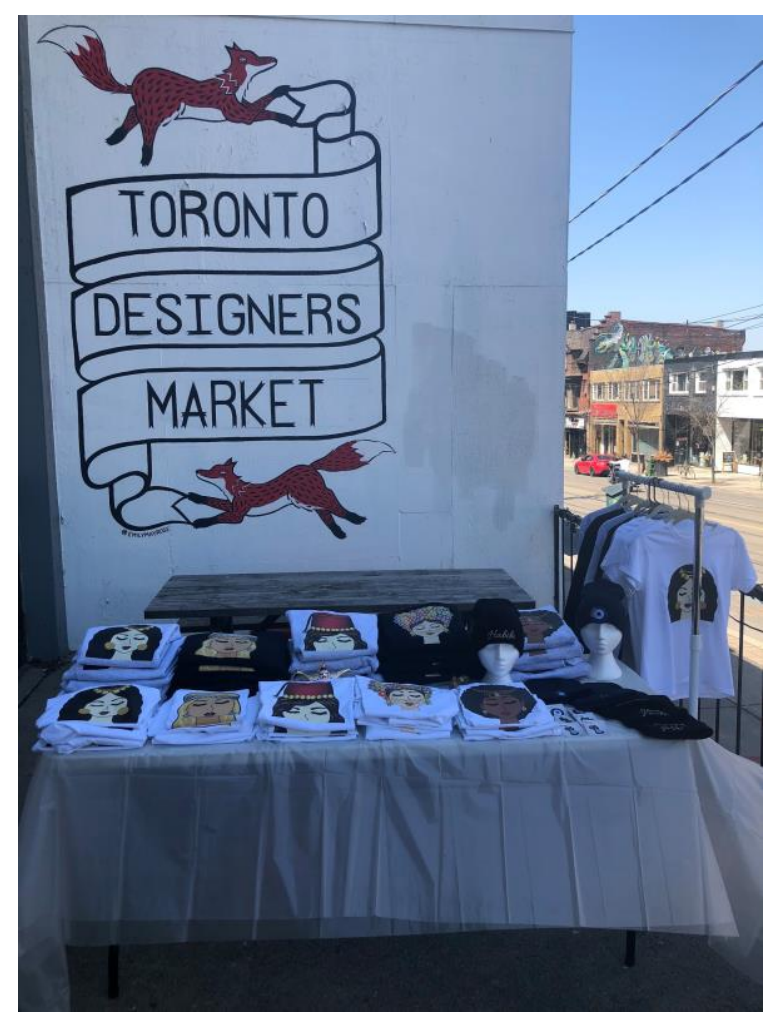

Noomi at Toronto Designers Market

I knew the location and demographic wasn't the most ideal for Noomi, but I thought I would give it a go regardless. Unfortunately, the result wasn't a success. Poor attendance and lack of a representation from my target market yielded poor results. The experience made me realize what 
works well for Noomi. In the future, being selective of the events I attend will be an important practice.

\title{
The Importance of Digital Media
}

The world population is continuing to grow while the internet is increasing in reach and capability. It would be virtually impossible to build brands like Noomi if it wasn't for digital media. Noomi solely sells online through www.noomishop.com and majority of its marketing strategies are through social media. Most of the website's traffic is sourced through Instagram. The most popular locations Noomi receives orders from are Canada, USA and UK.

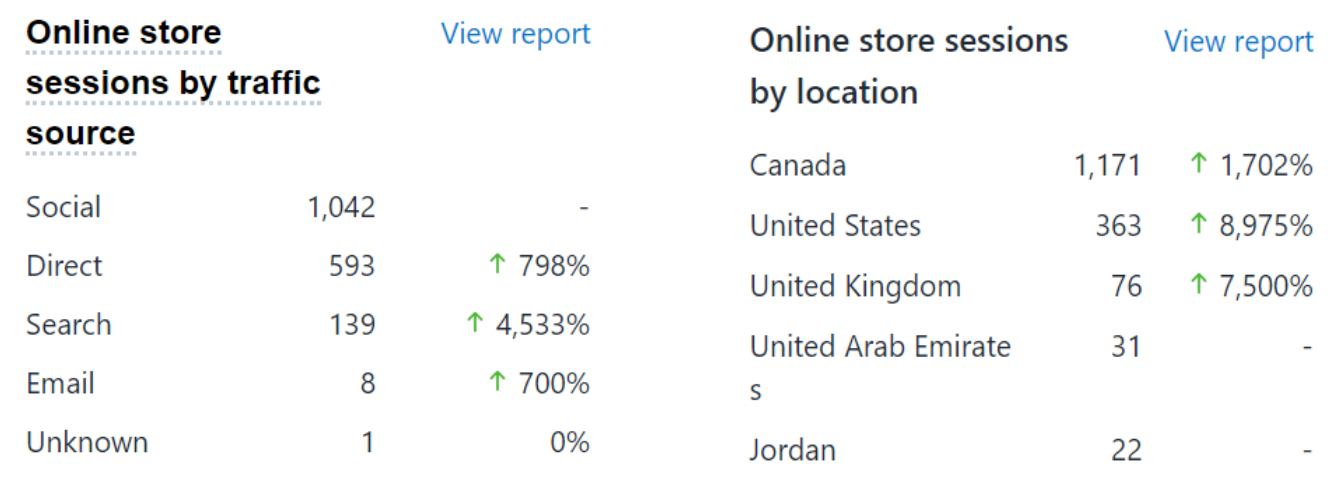

Analytics through Noomi's Shopify account. Data of 3 months (March 25 - June 25)

\begin{abstract}
Also, brand ambassadors are interested because they want to be part of the online community that Noomi offers. Customers receive a personal note telling them to hashtag \#NoomiShop. This strategy allows the customers to get involved in the creation of the brand while marketing the brand to their friends. Digital has become an integral part of every business, engraved deep within the supply chain of every business.
\end{abstract}




\section{What the Future Holds for Noomi}

Right now, Noomi's product line consists of 5 sweaters, 5 shirts, 7 beanies, and 3 pins. As of writing this paper, nearly 5 months have passed since the launch. The response for products has been incredible so far. I do hope to launch more products in the future, especially based on the data from customers to see what they liked the most or hope to see. Currently, the best sellers are the NOOR shirt, the MALAK shirt, the Habibi beanie, and the Evil Eye pin. The most requested products for the future are to have a men's collection and more designs for current customers to continue to purchase.

Marketing is continuous process, so I would need to further develop a marketing strategy and use different marketing tactics to see which results in the highest success rate through the amount of sales Noomi sold and through Noomi being mentioned by customers and press. I plan to continue to engage customers and brand ambassadors throughout the process to continue building the Noomi community. I will also be attending a range of events for the purpose of exposure. Events are already planned for the 10th August, 2018 for an Outdoor Screening and an additional event on the 25th of August called "GIRLBOSS." Noomi will be a vendor at both of these events. 


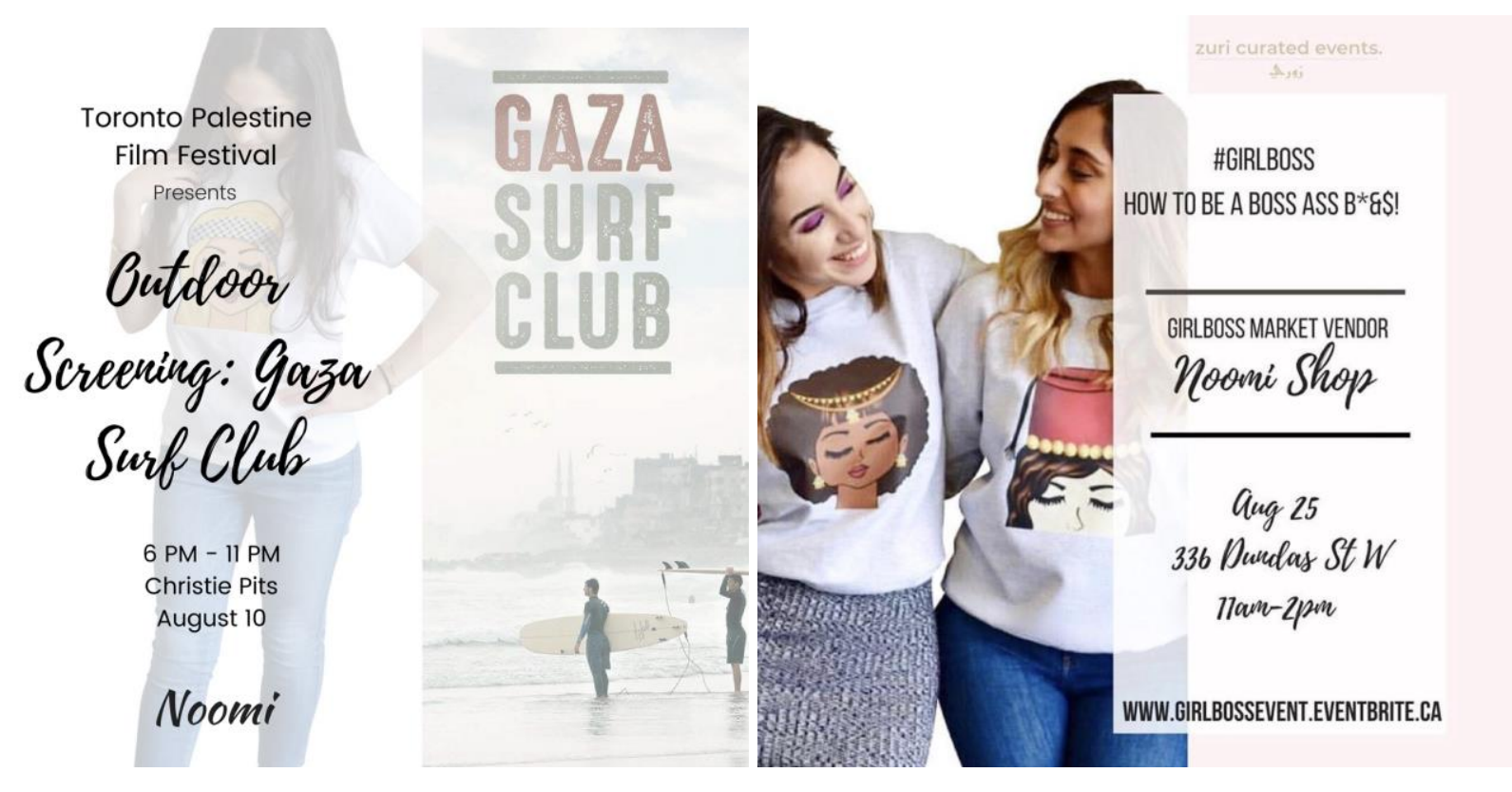

Instagram posts on events Noomi will be attending

\section{Conclusion: What I Learned}

It is evident that digital media continues to inspire young individuals like myself to create and

find market niches that would otherwise be left untouched. The ability to connect with the world and market through different mediums allows small businesses and individuals with little to no capital to compete with established brands. However, digital media not only connects your business to its target market, it is an integral part of every business. As for myself, the designs, products, customer service, and sales processed are all simplified using digital media. These tasks would otherwise be cumbersome to complete on my own. I am beyond thankful for the abilities that the MDM program has empowered me with and believe that there is no better skill set to acquire in the 21st century. My instructors and peers will continue to be the foundation of Noomi. 


\section{References}

Egusa C. (2016). PR For Startups: The Art of the Press Release in 7 Steps. Retrieved from https://500.co/pr-for-startups-the-art-of-the-press-release-in-7-steps/

Fryer B. (2003). Storytelling That Moves People. Harvard Business Review. Retrieved from https://hbr.org/2003/06/storytelling-that-moves-people

Patel N. (2015). 90\% Of Startups Fail: Here's What You Need To Know About The 10\%. Retrieved from

https://www.forbes.com/sites/neilpatel/2015/01/16/90-of-startups-will-fail-heres-what-you-needto-know-about-the-10/\#5d9742886679

The Three Frameworks You Need to Kick-start Sales. First Round Review. Retrieved from

http://firstround.com/review/the-three-frameworks-you-need-to-kick-start-sales/

Wise S. (2018). Want to Build a Billion-Dollar Business? Learn These Lessons from Dropbox.

Retrieved from https://www.inc.com/sean-wise/how-to-make-20b-in-10-years.html 